\title{
New Paradigm of COVID-19 with Pulmonary Tuberculosis: A Brief Review
}

\author{
Selvina
}

\section{ABSTRACT}

\begin{abstract}
The global threat of respiratory infectious diseases is constantly evolving among the world population. Severe acute respiratory syndrome coronavirus 2 is a novel member of the respiratory virus causing the coronavirus disease 2019 (COVID-19), an emerging disease characterized with pneumonia-like symptoms. Since it has been established as a worldwide pandemic, the cases of coronavirus infection are still growing and remain a global health concern. Meanwhile, tuberculosis also remains a great contributor to chronic respiratory communicable disease with cases still developing relentlessly. In a person manifested with chronic tuberculosis, co-infection of COVID-19 may occur and causes more severe clinical manifestations than tuberculosis single infection. On the other hand, it is also possible for people who have COVID-19 to be infected with new tuberculosis infection, especially if the individual lives in a developing country that tends to be tuberculosis endemic. Therefore, these two respiratory infections have become a worldwide double burden. This review provides a comprehensive overview of the new paradigm regarding these two worldwide emerging infectious diseases to provide a good understanding of their clinical aspects and to achieve the best possible future outcomes.
\end{abstract}

Keywords: COVID-19, SARS-CoV-2, tuberculosis, infectious diseases, communicable diseases, pandemic.

\section{INTRODUCTION}

Coronavirus disease 2019 (COVID-19) is a viral disease caused by severe acute respiratory syndrome coronavirus 2 (SARS-CoV-2). It firstly emerged in Huanan Seafood Wholesale Market in Wuhan, China, in December 2019 and continues to spread around the world [1]. COVID-19 has been declared a Public Health Emergency of International Concern on the $30^{\text {th }}$ of January, 2020 by the World Health Organization (WHO) [2]. It has caused over one million cases and 60.000 deaths worldwide by the start of April 2020 [3]. At least until the mid of May 2020, COVID-19 has also affected more than 16.000 Indonesian citizens with a mortality rate reaching $6.25 \%$ [4].

Meanwhile, the global health risk from another infectious respiratory chronic disease including pulmonary tuberculosis (TB) is still alarming. Pulmonary TB is known as one of the emerging communicable diseases, which is caused by the infection of Mycobacterium tuberculosis. Tuberculosis is the worldwide leading cause of death from an infectious disease among adults and childhood. It has also been considered a global public health emergency for the past 25 years [5], [6]. World Health Organization estimates that every year, around 10 million people were diagnosed with TB infection, making it becomes the top ten causes of mortality globally. The disease manifests mostly in adults, with a male to female ratio of 2:1. In 2018, most TB cases were in the WHO regions of
Published Online: December 30, 2020

ISSN: 2593-8339

DOI: $10.24018 /$ ejmed.2020.2.6.621

\section{Selvina*}

Department of Medicine, Puskesmas Kelurahan Semanan II, West Jakarta, Indonesia.

(e-mail: Selvinadr@gmail.com)

*Corresponding Author
South-East Asia (44\%), Africa (24\%), and Western Pacific (18\%) [7]. On the other hand, the incidence of TB in Indonesia remains high. In 2018, the incidence of TB has passed more than 450.000 cases, with a mortality rate reaching $2.5 \%$ [8].

In April 2020, WHO has stated a key point notes about continuing TB care during the COVID-19 pandemic, as these two respiratory diseases may co-infected each other and causing more distressing severity. Thus, it is important to perform a good effort in diagnosing and managing TB and COVID-19 co-infections, to ensure the safety of patients with both infections. It is also important to discuss a certain management to anticipate the patients with both COVID-19 and TB infection for having poorer management outcomes, especially if TB treatment is interrupted [9].

In Wuhan, three patients with pulmonary TB and COVID19 co-infection were found to have moderate to severe illness severity, as Yao reported. The patient eventually died due to acute respiratory distress syndrome, which led to respiratory and circulatory failure. They also concluded that co-infection between TB with severe acute respiratory syndrome manifestation from COVID-19 has been associated with intensive care unit admission [10].

Clinicians and public health officials should be concerned about the greater risks of health problems caused by chronic respiratory infections, such as TB in COVID-19 patients. In this review, the author provides a comprehensive evidencebased discussion of the new paradigm regarding these two 
worldwide emerging infectious diseases. This article aimed to present a good understanding of COVID-19 and TB clinical aspects and management, to achieve the best possible future outcomes from these global double burdens.

\section{TUBERCULOSIS}

Tuberculosis (TB) is an infectious disease caused by Mycobacterium tuberculosis (M. TB) bacteria. The infection is initiated by the aerosol inhalation of M. TB to the lung alveolar surfaces. From its primary infection in the lung, the bacteria can also spread to other organ systems. Thus, dividing the disease into pulmonary and extrapulmonary TB. The classic symptoms of $\mathrm{TB}$ in adults include a persistent cough, low-grade fever, lethargy, loss of weight, and night sweats [11].

Tuberculosis is one of the major global health problems. The diagnosis of TB can be obtained using several methods, such as microbiological culture examination, tuberculin skin tests (TST), interferon-gamma release assays (IGRAs), and nucleic acid amplification tests (NAAT). Currently, WHO has recommended the use of GeneXpert, which is a molecular assay that works rapidly and automatically. Using this method, the detection of TB infection can be improved.

However, in some developing countries as in Indonesia, the standard TB diagnosis has been applied based on clinical examination and sputum microscopy that is supported by chest radiology (Fig. 1). If the results of the sputum microscopy are negative, other tests can be performed such as microbiological culture and NAAT [12].

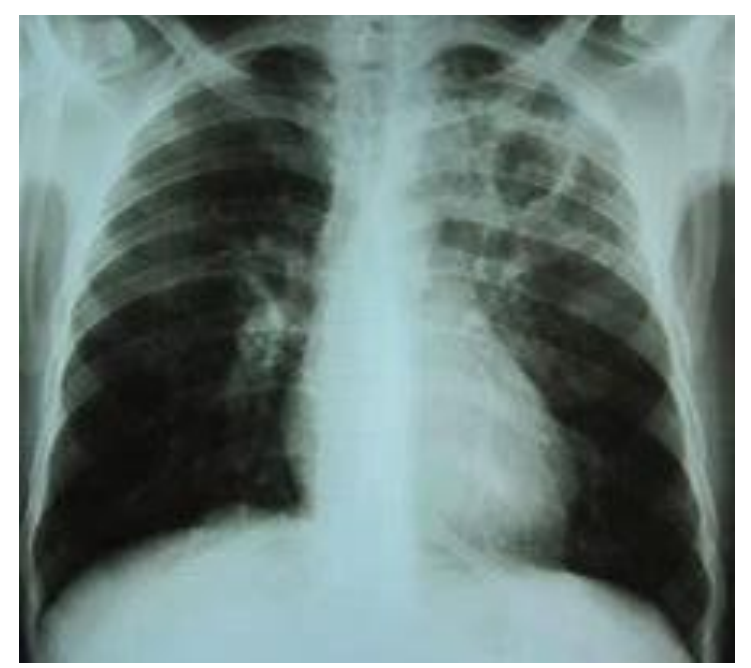

Fig. 1. Chest x-ray showing cavitary lesion on the upper left lung post-primary pulmonary TB [13].

\section{CORONAVIRUS DISEASE 2019}

Coronavirus disease 2019 is a novel respiratory syndrome found in humans. This causative virus is the SARS-CoV-2, which belongs to the same group as the zoonotic Middle East respiratory syndrome coronavirus (MERS-CoV) [14]. Clinical manifestations of COVID-19 are diverse, ranging from an asymptomatic infection to severe pneumonia-like symptoms, including fever, dry cough, weakness, dyspnea, muscle aches, diarrhea, viral conjunctivitis, and loss of taste and/or smell sensation [15]. The complications from clinical manifestations of COVID-19 may also affecting the respiratory, gastrointestinal, neurological, hepatic, renal, cardiac, hematological, ocular, olfactory, and cutaneous organ systems. The fever in SARS-CoV-2 virus infection is manifested from direct interaction of the virus and organum vasculosum of the lamina terminalis (OVLT). It may also be affected by indirect stimulation of cytokine release, including interleukin (IL)-1, IL-6, tumor necrosis factor (TNF- $\alpha$ ), which later act on the OVLT causing fever [16].

\section{Cellular Responses}

Patients diagnosed with TB can also be infected with COVID-19, which in turn might result in the deterioration of a patient's condition. A study from Gordon and colleagues evaluated the host-expression in correlation with COVID-19 and the interaction between 26 proteins of COVID-19 with 332 human proteins. It was seen that M. TB shares most host protein interaction partners (same interactome) as COVID19; thus, both infections are known to have high affinity towards lung tissue [17]. The human immune systems such as T-cells may be used to prevent infections in two ways, specifically through indirect mechanism as the cytotoxic mechanism (CD8 T-cells) and direct mechanism (CD4+ Tcells) where the virus, bacteria or any kind of pathogen has inside and multiplication along with cancel cells. The severity of a disease greatly depends on the responses of the T-cells [18]. After binding to Toll-Like Receptors (TLRs), i.e., TLR 2, TLR 4, TLR 7, both COVID-19 and M. TB activated Nuclear Kappa-Beta $(\mathrm{NF}-\mathrm{k} \beta)$, the transcription factor of macrophage that play a role as mediator of proinflammatory relishing factors. In vivo studies revealed that early infection of SARS-CoV-2 resulted in delayed cytokine release in respiratory epithelial cells, dendritic cells, and macrophage cells. On the other hand, the cells secreted small amounts of antiviral factors such as Interleukin (IL)-1 $\beta$, IL-6, tumor necrosis factor (TNF), and chemokines ligand motif (CCL2, CCL3, CCL5). These phenomena may elevate to the formation of granuloma in COVID-19 patients [19].

Surprisingly, the host immunity response against the M. TB pathogen has a similar mechanism. The chemokine CCL5 has been detected in TB patient's immune systems. The CCL5, as well as CCL3, CCL4 promote a large amount of early T-cells migration to $\mathrm{M}$. TB infected sites. When CCL ligands attached to its receptor (CCR), the localized infected cells would later spread into the other cells, forming granulomas, and countering against M.TB. In COVID-19 patients, an activated inflammatory process that is related to the increased secretion of cytokines, i.e., TNF $\alpha$, IL-6, IL-10, is named cytokine storm. It is defined as an excessive inflammatory reaction; thus, cytokines are rapidly produced in a large amount in response to microbial infection [19]. The constant presence of high viral load and antigen levels, antiinflammatory mediators, such as interleukin (IL-10) and transforming growth factor (TGF) and regulatory $\mathrm{T}$ (Treg) cells, may contribute to the loss or paralysis of T-cells function. The exhausted T-cells lead to the condition known as T-cells dysfunction that may happen throughout the chronic infections, such as TB infection. These exhausted Tcells have an impact on the cells proliferative capacity and increased apoptosis rate. However, although COVID-19 is 
not a chronic disease, it showed a decreased number of Tcells, CD4+ and CD8 [18]. The mechanism of T-cells exhaustion is similar both in TB and COVID-19. Elevation of IL-6 and IL-10 can be found, which was the key role in the T-cells exhaustion mechanism. The mechanism of direct action of IL- 6 has been shown by signal transducer and activator of transcription 3 (STAT-3) activation in CD4 cells. Moreover, IL-10 also plays role as an inhibitory cytokine that induces T-cells exhaustion. In both cases, TB and COVID-19 patients have a high level of IL-10. Some studies have shown that blocking IL-10 may help to restore T-cells function and improves viral control to reverse the exhaustion [17]-[19].

\section{CORONAVIRUS DiSEASE 2019 AND PULMONARY TUBERCULOSIS}

Bacterial TB and viral respiratory infectious diseases, such as COVID-19, have certain similarities. Both of them mainly invade susceptible populations through droplet transmission or other transmission routes from infectious sources (Table 1). Liu and colleagues reported three out of 83 patients with
SARS based on chest radiographs with consistent findings with active disease identified as pulmonary TB. Patient 1 was also diagnosed with bacteriologically confirmed TB when he was diagnosed with SARS, during the SARS epidemic in 2003 [20]. In Singapore, two out of 236 patients with probable COVID-19 were also co-infected with TB. One of them suddenly developed a dry cough and was later identified as having pulmonary TB after nearly full recovery from COVID-19. This condition was caused by COVID-19 that induces a temporary suppression of cellular immunity, and further predisposed the two patients to aggravate reactivation or new infection with TB [21].

The difference of radiographic imaging finding between TB and COVID-19 by using Computed Tomography (CT) is the ground-glass opacities (GGO) (Fig. 2), which are the most common patterns found in COVID-19 patients. Pan and colleagues studied the lung changes on chest $\mathrm{CT}$ during the recovery of 21 patients. Initial lung findings on chest $\mathrm{CT}$ were small subpleural GGO that grew larger with a crazy-paving pattern and consolidation in the following two weeks. Eventually, the lesion was absorbed, leaving extensive GGO and subpleural parenchyma bands [22].

TABLE I: COMPARISON OF TUBERCULOSIS AND CORONAVIRUS DISEASE 2019 [27]-[30]

\begin{tabular}{|c|c|c|}
\hline & Tuberculosis & COVID-19 \\
\hline Pathogen & Mycobacterium tuberculosis & Severe acute respiratory syndrome coronavirus 2 (SARS-CoV-2) \\
\hline Mode of spread & Airborne & Droplet (direct spread and contact) \\
\hline Infectiousness & $\begin{array}{l}\text { Range from less than } 1 \text { to up to } 4 \text { people infected per one } \\
\text { person with TB }\end{array}$ & $\begin{array}{l}\text { Currently average of } 2.2 \text { people infected per one person with } \\
\text { COVID- } 19\end{array}$ \\
\hline Incubation period & $\begin{array}{l}\text { Variable, symptoms develop weeks to a year after } \\
\text { exposure. }\end{array}$ & $1-2$ weeks \\
\hline Laboratory features & $\begin{array}{l}\text { High erythrocyte sedimentation rate, leukopenia, } \\
\text { lymphopenia, high thrombocytopenia, anemia. }\end{array}$ & $\begin{array}{l}\text { Decreased albumin, high C-reactive protein, high aspartate } \\
\text { aminotransferase, high alanine aminotransferase, high creatinine } \\
\text { kinase, leukocytosis, high bilirubin, high creatinine. }\end{array}$ \\
\hline Onset of symptoms & Gradual onset of symptoms often over weeks or longer. & Acute onset of symptoms within days \\
\hline Symptoms & Cough, low-grade fever, weakness, shortness of breath. & $\begin{array}{l}\text { Fever, fatigue, dry cough. Development of dyspnea, loss of smell, } \\
\text { cough with sputum is less common (about } 27 \% \text { ). }\end{array}$ \\
\hline $\begin{array}{l}\text { Clinical Sample used } \\
\text { diagnoses }\end{array}$ & $\begin{array}{l}\text { Sputum tests for cough. Other samples depending on } \\
\text { symptoms }\end{array}$ & $\begin{array}{l}\text { Nasopharyngeal or oropharyngeal swab or wash in ambulatory } \\
\text { patients, sputum or endotracheal aspirate or bronchoalveolar } \\
\text { lavage may be used in patients with severe respiratory disease. }\end{array}$ \\
\hline Diagnostic Tests & $\begin{array}{l}\text { Sputum smear microscopy, culture test, TB interferon- } \\
\text { gamma release assays, chest X-rays, serological tests, } \\
\text { tuberculin skin tests, molecular assays as GeneXpert and } \\
\text { TB TrueNat. }\end{array}$ & $\begin{array}{l}\text { Viral load detection (RT-PCR), serological-antibody test (IgM } \\
\text { and IgG). }\end{array}$ \\
\hline Prevention & $\begin{array}{l}\text { Treatment for those with known contacts with TB. Good } \\
\text { respiratory hygiene measures. }\end{array}$ & $\begin{array}{l}\text { Social distancing, good respiratory hygiene measures, and } \\
\text { handwashing with soap for at least } 20 \text { seconds. }\end{array}$ \\
\hline Treatment & Anti-TB treatment: combination of antibiotics & Currently supportive treatments. Many drug trials underway \\
\hline Vaccine & $\begin{array}{l}\text { BCG has some protective effects, particularly or childhood } \\
\text { aged. }\end{array}$ & Research for a new vaccine is ongoing. \\
\hline
\end{tabular}

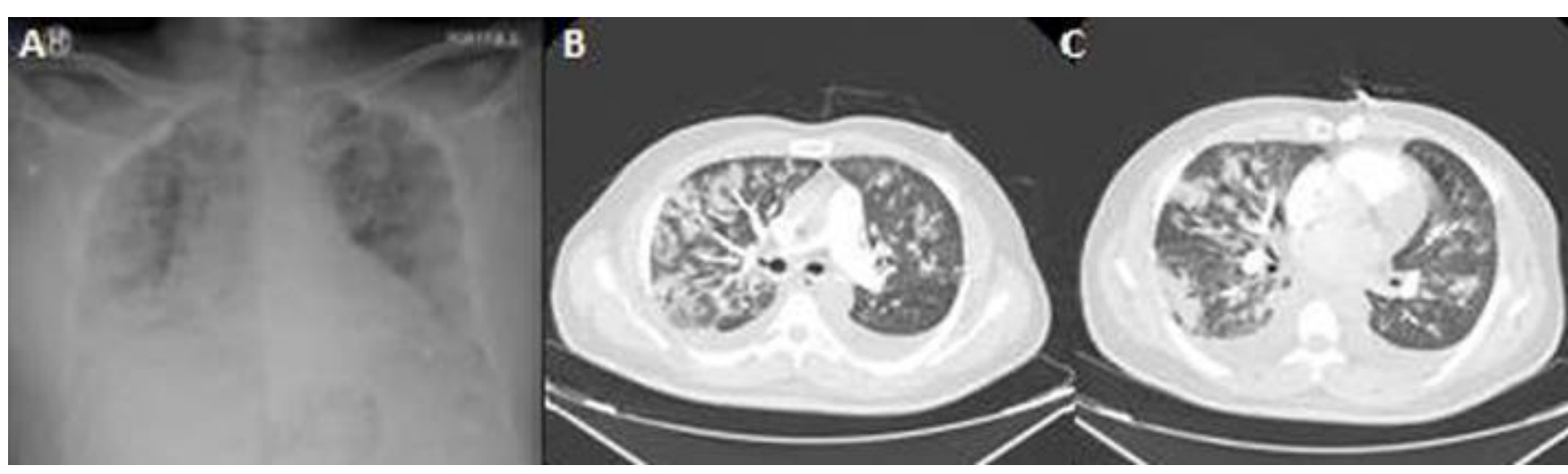

Fig. 2. (A) Portable chest X-ray revealed bilateral interstitial infiltrates, (B \& C) chest computed tomography scans revealed bilateral diffuse ground-glass opacities with mainly a peripheral and lower lobe distribution [23]. 
TABLE II: DIFFERENCE IN CLINICAL MANIFESTATION OF TB AND COVID-19 PATIENTS [34]

\begin{tabular}{|c|c|c|}
\hline & Tuberculosis & COVID-19 \\
\hline Speed of onset & $\begin{array}{l}\text { Typically develop over a much longer period (weeks or } \\
\text { longer) }\end{array}$ & $\begin{array}{l}\text { Fever and cough in COVID-19 have a rapid onset and an } \\
\text { incubation period of about two days to two weeks (within days) }\end{array}$ \\
\hline Coughing & Usually productive of sputum and even blood. & $\begin{array}{l}\text { While in uncomplicated COVID-19 it is more commonly a dry } \\
\text { cough. }\end{array}$ \\
\hline Shortness of breath & $\begin{array}{l}\text { In TB this usually occurs at a much later stage or as a long- } \\
\text { term sequela. }\end{array}$ & It develops early after onset in COVID-19 \\
\hline $\begin{array}{l}\text { Outbreak in the same } \\
\text { household or a } \\
\text { congregate setting }\end{array}$ & $\begin{array}{l}\text { While in TB the progression is rarely abrupt and may only } \\
\text { become apparent after several months. }\end{array}$ & $\begin{array}{l}\text { In case of COVID-19 usually becomes apparent within a week or } \\
\text { two. }\end{array}$ \\
\hline
\end{tabular}

Clinically, the primary TB manifests with three main entities, i.e., parenchymal disease, lymphadenopathy, and pleural effusion. At CT findings, the appearance of parenchymal consolidation in primary TB is most commonly dense and homogeneous [24]. In most cases of reactivation $\mathrm{TB}$, more than one pulmonary segment is involved, with bilateral disease seen in one-third to two-thirds of cases. On CT scans, bronchogenic spread can be identified in $95 \%$ of patients with post-primary TB. About $50 \%$ of patients manifested for having pulmonary cavitation, the hallmark of post-primary TB [25].

Yousaf and colleagues reported three patients with TB based on a positive sputum smear for acid-fast bacilli (AFB) accompanied by COVID-19 co-infection based on nasopharyngeal swab. All patients have different symptoms, such as cough $(83.3 \%)$, fever $(50 \%)$, myalgias $(33.3 \%)$, headache $(16.6 \%)$, and fatigue $(16.6 \%)$. Another common symptom was weight-loss. None of the patients reported diarrhea, vomiting, loss of smell and taste sensation. All patients had cavitary lesions identified on imaging. They also stated that the co-infection negatively correlates with worse outcomes if recognized early with prompt treatment [26].

Co-infection of TB with COVID-19 becomes a particular concern due to several reasons. First, the diagnosis of TB is likely to be missed due to non-specific clinical features in both conditions with a lack of radiological findings specific to TB. Second, the disease itself is an immunomodulator in moderate to severe COVID-19 that may lead to reactivation of latent TB, especially in high endemic areas like Indonesia. Third, the pre-existing TB disease and underlying lung condition will affect the clinical categorization in COVID-19 severity. Fourth, co-existing active TB disease may predispose to more severe illness. Lastly, there is a possibility of drug-to-drug interactions (i.e., rifampicin and lopinavir or ritonavir), as well as additive hepatotoxicity (i.e., remdisivir) due to simultaneous use of anti-tuberculosis drugs and the current available COVID-19 therapeutics strategies [31,32].

\section{Clinical Manifestation of Coronavirus Disease 2019 AND PULMONARY TUBERCULOSIS CO-INFECTION}

Clinical manifestations of active and/or latent TB in COVID-19 are not fully elucidated. In a most recently published cohort study of 49 TB patients with COVID-19, which were recruited by the Global Tuberculosis Network, no outcome analysis was available [33]. Togun and colleagues reported that the clinical manifestations of TB and COVID19 can be similar, with cough, fever, breathlessness, and malaise being common in both [34]. Some studies reported that both COVID-19 and TB commonly involve the respiratory systems and have similar symptoms, although the biological agents and incubation period from exposure to disease are different (Table 2). Fever and cough in COVID19 patients are characterized by rapid onset with an incubation period of about one to two weeks, whereas clinical manifestations in TB patients typically manifest over more than two months. Moreover, shortness of breath in TB usually occurs at a much later stage or as a long-term sequela, which is different with COVID-19 that occurs right after the first onset of the disease [30]-[34]

Co-infection TB with COVID-19 is diagnosed clinically based on clinical manifestation similarities, such as respiratory tract infection symptoms. However, various radiological findings characterized by specific pulmonary lesions can be found [35]. An accurate diagnostic modality should be made available to avoid overdiagnosis in one over another. Tuberculin Skin Test (TST), as well as the interferon-gamma release assays (IGRA), have a great sensibility and specificity and are widely used for TB screening [36]. Given their results are influenced by the host's immune response after BCG vaccination, there is a gap for diagnostic errors in individuals with an impaired immune system, such as in a concurrent severe infection. Increased age, low peripheral lymphocyte count, high body mass index, and negative results, could lead to missing TB diagnosis. Moreover, an excess of inflammatory markers could affect IGRAs sensitivity, and the high value of C-reactive protein (CRP) might be a confounder for false-negative results [37]. It has been observed that high CRP and low peripheral lymphocyte counts could occur within a few days of exposure to SARS-CoV-2. Therefore, this observation may lead to the possibility that a patient with latent TB or TB sequel may have a false-negative IGRA. As SARS-CoV-2 has not been identified for a few months [38].

\section{MANAGEMENT OF CORONAVIRUS DiseASE 2019 AND PULMONARY TUBERCULOSIS CO-INFECTION}

Isoniazid, rifampicin, ethambutol, and pyrazinamide are known as direct anti-M. TB agents. However, multidrugresistant (MDR) TB extensively occurs in co-infection COVID-19 [38]. The potential host-directed therapeutic, used in COVID-19 patients, currently remains no evidence from Randomized Clinical Trials (RCTs) potential therapy to improve outcome in COVID-19 patients. Nevertheless, the use of ribavirin, lopinavir/ritonavir (effective dose $400 \mathrm{mg}$ orally every 12 hours), oseltamivir ( $75 \mathrm{mg}$ two times per day for 5 days), and other agents is also been considered, including host directed-therapy (HDT) [39]. This review focused on anti-cytokine monoclonal agents use to reduce the cytokine storm and prevent T-cell exhaustion is one of the HDT targets. Protective T-cells immunity against M. TB at 
the site of infection is mediated by Th1 cytokines, such as interferon (IFN)- $\gamma$, TNF- $\alpha$, IL-2, and IL- 6 . The exhausted Tcells condition might incriminate $\mathrm{M}$. TB and COVID-19 elimination process [40]. There were monoclonal antibodiesdirected agents such as tocilizumab, sarilumab, thalidomide, and bevacizumab as adjuvant therapy in TB with COVID-19 patients (Fig. 3).

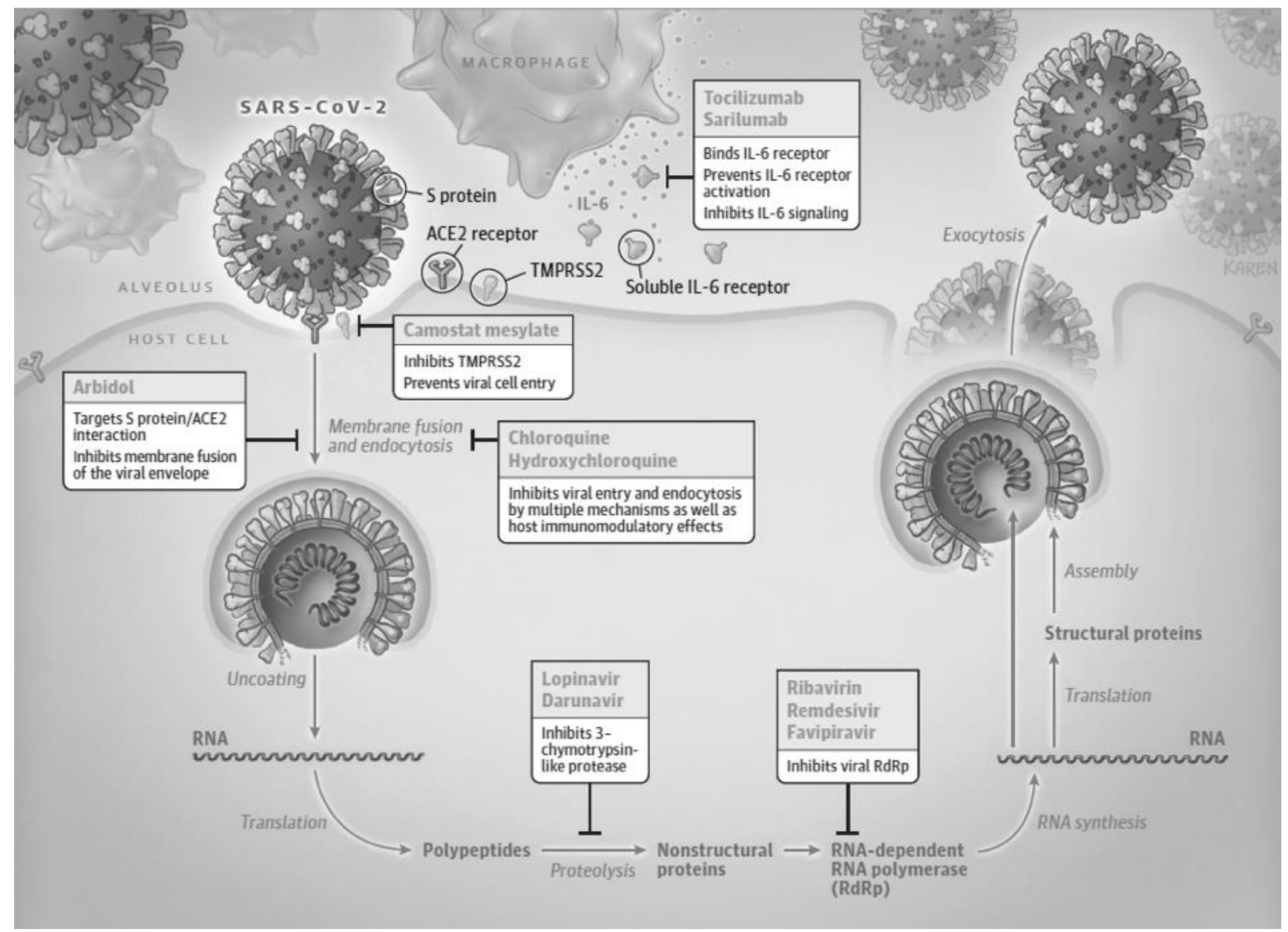

Fig. 3. Potential drugs target according of SARS-CoV-2 viral life cycle [39].

Thalidomide is known as anti-emetic agents. Later discoveries have shown its potent anti-inflammatory and immunomodulator. It can suppress TNF- $\alpha$ production in macrophages and reduces systemic inflammation. On the other hand, tocilizumab, sarilumab, and bevacizumab are IL6 receptor antagonists. Tocilizumab competitively inhibits IL-6 binding to their receptors, with their membranous-bound and soluble form. Tocilizumab slowed down TB infection through the inhibition of M. TB multiplication in blood stem cells [41]. It is also potentially an effective and safe way to reduce the mortality rate caused by COVID-19 by inhibits the "storm" through IL-6 [42].

The dosage tocilizumab is $8 \mathrm{mg} / \mathrm{kg}$ (maximum dose of 800 $\mathrm{mg}$ at one time), given slowly in $100 \mathrm{~mL}$ normal saline (NS) over 1 hour. It can be repeated once after 12-24 hours if needed. Active TB and neutropenia are contraindicated to use tocilizumab [43]. Plasma exchange via convalescent plasma may be considered for COVID-19 patients, as this procedure may be indicated for severe conditions that do not show improvement (oxygen requirement is progressively increasing) despite the use of steroids. The dose ranges from 4 to $13 \mathrm{~mL} / \mathrm{kg}$, and usually, a single dose of $200 \mathrm{~mL}$ is given slowly over 2 hours [43]. Prophylactic anticoagulation using low molecular weight heparin (LMWH) (i.e. enoxaparin 40 mg subcutaneously) should be given in moderate (once a day) to severe patients (two times a day). In the case of pregnant COVID-19 patients, needful consultations should be taken from obstetric and gynecologist specialist [41].

Faqihi and colleagues reported a case study involving $38.8 \%$ of TB patients diagnosed with COVID-19 during antiTB treatment, with limited or no protection against COVID19. The study reported a case from 1 patient (Fig. 1) with TB on first-line anti-TB therapy and antiviral treatment for COVID-19. There were not any side effects found, although theoretically, it may increase the risk of the occurrence of side effects such as liver toxicity. Hence, clinicians should monitor carefully patients under treatment for TB and COVID-19 side effects of combination therapies and drug interactions [23].

\section{BACILlus CALMETTE-GUERIN (BCG) VACCINE IN CORONAVIRUS DISEASE 2019}

The Bacillus Calmette-Guerin (BCG) vaccine is a live attenuated strain derived from an isolate of Mycobacterium bovis. The use of the BCG vaccine has been shown a tremendous effect in averting severe cases of adult or childhood TB [46]. The BCG vaccine may enhance the general innate immune response, stimulating natural killer 
(NK) cells, monocytes, and macrophages, and protect against other pathogens [23].

In terms of COVID-19, a population-based study examining the cohort of Israeli adults aged 35-41 years found that BCG vaccination in childhood was associated with a similar rate of positive tests for COVID-19 compared with no vaccination (difference value $1.3 \% ; 95 \% \mathrm{CI}=0.3-2.9 \%$; $p$ value $=0.09$ ). Their study showed that the $B C G$ vaccine may not reduce the likelihood of acquiring SARS-CoV-2 [44]. A retrospective cohort study conducted from community population in the United States, aged 18 years and older (median age 39.5 years, interquartile range 27.0-50.0 years) found that COVID-19 patients with BCG vaccination were less likely to require hospital admission (3.7\% vs. $15.8 \%, p$ value $=0.019$ ) [45]. Escobar and colleagues stated that the incidence and mortality rate from COVID-19 was significantly lower in countries with universal BCG vaccination as compared to countries without such policy [46]. The mechanism of the BCG vaccine in improving COVID-19 manifestation is by increasing the clearance of apoptotic or dead cells by alveolar phagocytes. Based on an experimental study by Cespedes and colleagues, it is known that the BCG vaccine brings a TH1/TH17 T-cells repertoire. This condition then facilitates an efficient virus clearance and protects the lung system from the inflammation process. Moreover, the BCG vaccine is a strong promoter of T-helper type 1 immune systems [47].

\section{CONCLUSION}

The clinicians should have a high suspicion of the present pandemic for both TB and COVID-19 infection. Coinfections with TB must always be suspected in addition to COVID-19, especially in the current scenario of a patient with respiratory tract infection with non-specific clinical features and unexplained or prolonged clinical course. Larger prospective studies are required to investigate further the diagnosis, management, and clinical course of active and/or latent TB with COVID-19 patients.

\section{REFERENCES}

[1] R. Lu, X. Zhao, J. Li, et al., "Genomic characterization and epidemiology of 2019 novel coronavirus: implication for virus origins and receptor binding," Lancet, vol. 395, no. 10224, pp. 565-574, Feb 2020.

[2] World Health Organization (2020). Coronavirus disease (COVID-19) Pandemic - Emergency Use Listing Procedure (EUL) open for in vitro diagnostics [Online]. Available from: https://www.who.int/diagnostics _laboratory.

[3] C. Sohrabi, Z. Alsafi, N. O'Neill, et al., "World Health Organization declares global emergency: A review of the 2019 novel Coronavirus (COVID-19)," Int J Surg., vol. 76, pp. 71-76, 2020.

[4] Kemenkes RI, "Coronavirus disease 2019," Peraturan Menteri Kesehatan Republik Indonesia, no. 9, pp. 2-6, 2020.

[5] R.R. Nathavitharana, J.S. Friedland, "A tale of two global emergencies: tuberculosis control efforts can learn from the Ebola outbreak," Eur Respi J., vol. 46, pp. 293-296, 2015.

[6] S. Yadav, G. Rawal, "The case of pulmonary tuberculosis with COVID-19 in an Indian male: a first of its type case ever reported from South Asia," PAMJ, vol. 36, no. 374, pp. 1-5, 2020.

[7] World Health Organization (2019). Global Tuberculosis Report 2019 [Online]. Available from: https://apps.who.int/iris/bitstream/handle/
[8] Depkes RI, "Infodatin Tuberkulosis," Kementerian Kesehatan RI, pp. 1-10, 2018.

[9] World Health Organization, "Information Note Tuberculosis and COVID-19: Considerations for Tuberculosis (TB) care," World Health Organization, pp. 1-10, 2020.

[10] Z. Yao, J. Chen, Q. Wang, et al., "Three patients with COVID-19 and pulmonary tuberculosis, Wuhan, China, January-February 2020," Emerging Infectious Diseases, vol. 26, no. 11, pp. 2754-2757, 2020.

[11] K.N. Pravin, E. Chourasia, "Use of GeneXpert assay for diagnosis of tuberculosis from body fluid specimens, a 2 years stud," $J$ Microbiol Biotechnol., vol. 1, no. 1, pp. 000105, 2016.

[12] A.S. Piatek, M. van Cleeff, H. Alexander, et al., "GeneXpert for TB diagnosis: planned and purposeful implementation," Glob Health Sci Pract., vol. 1, no. 1, pp. 18-23, 2013.

[13] B.A. al Ubaidi, "The radiological diagnosis of pulmonary tuberculosis (TB) in primary care," J Fam Med Dis Prev., vol. 4, no. 1, pp. 1-7, 2018.

[14] Z.A. Memish, J.A. Al-Tawfi, A. Assiri, et al., "Middle East respiratory syndrome coronavirus disease in children," Pediatr Inf Dis J., vol. 33 , pp. 904-906, 2014.

[15] D. Wang, B. Hu, C. Hu, et al., "Clinical characteristics of 138 hospitalized patients with 2019 novel Coronavirus-infected pneumonia in Wuhan, China," JAMA vol. 323, pp. 1061-1069, 2020.

[16] E.J. Walter, S. Hanna-Jumma, M. Carraretto, et al., "The pathophysiological basis and consequences of fever," Crit Care, vol. 20, pp. 200, 2016

[17] D.E. Gordon, G.M. Jang, M. Bouhaddou, et al., "A SARS-CoV-2 protein interaction map reveals targets for drug repurposing," Nature, pp. 459-468, 2020

[18] M.Z. Tay, C.M. Poh, L. Rénia L, et al., "The trinity of COVID-19: Immunity, inflammation and intervention," Nat Rev Immunol., vol. 20 no. 6 , pp. $363-374,2020$.

[19] B. Diao, C. Wang, Y. Tan, et al., "Reduction and functional exhaustion of T cells in patients with Coronavirus Disease 2019 (COVID-19)," Front Immunol., vol. 11, pp. 827, 2020

[20] W. Liu, A. Fontanet, P. Zhang, et al., "Pulmonary tuberculosis and SARS, China,” Emerge Infect Dis., vol. 12, pp. 707-709, 2006.

[21] J.G. Low, C.C. Lee, Y.S. Leo YS, et al., "Severe acute respiratory syndrome and pulmonary tuberculosis," Clin Infect Dis., vol. 38, pp e123-125, 2004.

[22] F. Pan, T. Ye, P. Sun, et al., "Time course of lung changes on chest CT during recovery from 2019 novel coronavirus (COVID-19) pneumonia," Radiology, vol. 295, no. 3, pp. 715-721, 2020.

[23] F. Faqihi, A. Alharthy, A. Noor, et al., "COVID-19 in a patient with active tuberculosis: a rare case-report," Respiratory Medicine Case Reports, vol. 31, pp. 101146, 2020.

[24] L. Cardinale, D. Parlatano, F. Boccuzzi, et al., "The imaging spectrum of pulmonary tuberculosis,” Acta Radiol, vol. 56, pp. 557-564, 2015.

[25] J. Burrill, C.J. Williams, G. Bain, et al., "Tuberculosis: A radiologic review," RadioGraphics, vol. 27, pp. 1255-1273, 2007.

[26] Z. Yousaf, A.A. Khan, H.A. Chaudhary, et al., "Cavitary pulmonary tuberculosis with COVID-19 coinfection," ID Cases, pp. 1-3, 2020.

[27] Centers for Disease Control and Prevention (2020). Tuberculosis [Online]. Available at https://www.who.int/news-room/fact-sheets/ detail/tuberculosis

[28] F. Abay, A. Yalew, A. Shibabaw, et al., "Hematological abnormalities of pulmonary tuberculosis patients with and without HIV at the University of Gondar Hospital, Northwest Ethiopia: a comparative cross-sectional study," Tuberc Res Treat, pp. 5740951, 2018.

[29] P.R. Sharma, S. Jain, R.N. Bamezai et al., "Utility of serum LDH isoforms in the assessment of mycobacterium tuberculosis induced pathology in TB patients of Sahariya tribe," Indian J Clin Biochem. vol. 25, pp. 57-63, 2010.

[30] A.J. Rodriguez-Morales, J.A. Cardona-Ospina, E. Gutiérrez-Ocampo, et al., "Clinical, laboratory and imaging features of COVID-19: a systematic review and meta-analysis," Travel Med Infect Dis, vol. 34 , pp. 101623, 2020.

[31] Y. Liu, L. Bi, Y. Chen, et al. (2020). Active or latent tuberculosis increases susceptibility to COVID-19 and disease severity. Infectious Diseases [Online] Available from: http: //medrxiv.org/.

[32] World Health Organization (2020). Summaries of Evidence Experimental Therapeutics [Online]. Available from: https://www. who.int/ebola/drc-2018/.

[33] M. Tadolini, L.R. Codecasa, J.M. García, "Active tuberculosis, sequelae and COVID-19 co-infection: first cohort of 49 cases," Eur Respir J., vol. 56, pp. 2001398, 2020. 
[34] T. Togun, B. Kampmann, N.G. Stoker, et al., "Anticipating the impact of the COVID-19 pandemic on TB patients and TB control programmes," Ann Clin Microbiol Antimicrobe, vol. 19, pp. 1-6, 2020.

[35] D. Raoult, A. Zumla, F. Locatelli et al., "Coronavirus infections: epidemiological, clinical and immunological features and hypotheses," Cell Stress, vol. 4, no. 4, pp. 66-75, 2020.

[36] L. Di, Y. Li, "The risk factor of false-negative and false positive for TSPOT.TB in active tuberculosis," Journal of Clinical Laboratory Analysis, vol. 32, no. 2, pp. e22273, 2018.

[37] Y.S. Kwon, Y.H. Kim, K. Jeon, "Factors that predict negative results of quantiferon-TB gold in-tube test in patients with culture-confirmed tuberculosis: a multicenter retrospective cohort study," PLoS One, vol. 10, no. 6, pp. e0129792, 2015.

[38] W. Zhang, Y. Zhao, F. Zhang, "The use of anti-inflammatory drugs in the treatment of people with severe coronavirus disease 2019 (COVID19): the perspectives of clinical immunologists from China," Clinical Immunology, vol. 214, pp. 108393, 2020.

[39] J.M. Sanders, M.L. Monogue, T.Z. Jodlowski, et al., "Pharmacologic treatments for Coronavirus disease 2019 (COVID-19): a review,' JAMA vol. 323 , no. 18 , pp. 1824-1836, 2020.

[40] H. Jamshaid, F. Zahid, U.I. Din et al., "Diagnostic and treatment strategies for COVID-19," AAPS Pharma Sci Tech., vol. 21, no. 222 pp. $1-14,2020$

[41] L.J. Ho, S.F. Luo, J.H. Lai, "Biological effects of interleukin-6: clinical applications in autoimmune diseases and cancers," Biochem Pharmacol., vol. 97, no. 1, pp. 16-26, 2015.

[42] X. Xu, M. Han, T. Li, et al., "Effective treatment of severe COVID-19 patients with tocilizumab," Proc Natl Acad Sci USA, vol. 117, no. 20 , pp. 10970-10975, 2020.

[43] Indian Ministry of Health and Family Welfare (2020). Clinical Management Protocol for COVID 19 [Online]. Available from: https://www.mohfw.gov.in/.

[44] U. Hamiel, E. Kozer, I. Youngster, "SARS-CoV-2 rates in BCGvaccinated and unvaccinated young adults," JAMA, vol. 323, no. 22 pp. 2340-2341 2020.

[45] C.H. Weng, A. Saal A, W.W. Butt, "Bacillus Calmette-Guérin vaccination and clinical characteristics and outcomes of COVID-19 in Rhode Island, United States: a cohort study," Epidemiol Infect, pp. 19, 2020.

[46] L.E. Escobar, A. Molina-Cruz, C. Barillas-Mury, "BCG vaccine protection from severe coronavirus," PNAS Appl Biol Sci, pp. 1-7, 2020.

[47] P.F. Cespedes, E.R. Jurado, J.A. Ezpinoza, et al., "A single, low dose of cGMP recombinant BCG vaccine elicit protective $\mathrm{T}$ cell immunity against the human respiratory syncytial virus infection and prevents lung pathology in mice," Vaccine vol. 35, no. 5, pp. 757-76, 2017. 